\title{
A precarização do trabalho no contexto da pandemia de Covid-19: uma leitura do filme Estou me guardando para quando o Carnaval chegar (2019)
}

The precariousness of work in the context of the Covid-19 pandemic: a reading of the film Waiting for the Carnival (2019)

Matheus Guimarães Costa

Universidade Estadual de Feira de Santana. Departamento de Tecnologia.

\section{RESUMO}

Diante da urgência em discutir relações de trabalho e suas implicações nas subjetividades dos sujeitos, conforme compreendemos que a estrutura social brasileira está apoiada sobre a exploração laboral de certos grupos sociais, ainda mais quando o COVID-19 e a situação de desequilbrio do sistema público de saúde, tem escancarado as desigualdades sociais. Partindo do filme "Estou me guardando para quando o carnaval chegar" (2019), de Marcelo Gomes, esse texto percorre pelas questões que tangem o mundo do trabalho e a informalidade do mesmo,

\section{ABSTRACT}

In view of the urgency to discuss labor relations and their conclusions on the subjects' subjectivities, as we understand that a Brazilian social structure is supported on the labor exploitation of certain social groups, even more so when COVID-19 and the unbalanced situation of the public health system. health, has wide open social inequalities. Starting from the film "I'm saving myself for when the carnival arrives" (2019), by Marcelo Gomes, this text goes through the issues that touch the world of work and the informality of it, characteristic of the production of jeans in Toritama, característica da produção do jeans em Toritama, Pernambuco, servindo como ponto de discussão para a realidade atual de muitos trabalhadores no país.
KEYWORDS: Work; Brazil; inequality;

Pernambuco, serving as discussion point for the current reality of many workers in the country.
PALAVRAS-CHAVE: Trabalho; Brasil; health.

desigualdade; saúde. 
“E quem me vê apanhando da vida

Dúvida que eu vá revidar

Tô me guardando pra quando o carnaval chegar"

Chico Buarque - Quando o Carnaval chegar

“Metrópoles sufocam, são necrópoles que não se tocam

Então se chocam com o sonho de alguém

São assassinas de domingo a pausar tudo que é lindo

Todos que sentem isso são meus amigos, também"

Emicida - Cananéia, Iguape e llha Comprida

Na cidade de Toritama, interior do estado de Pernambuco, às margens do rio Capibaribe, está localizado um dos polos mais produtivos do setor de vestuário da região Nordeste, onde mais de 20 milhões de jeans são produzidos, por ano, em fábricas de fundo de quintal. Com um pouco mais de 44 mil habitantes, a produção dessa cidade representa 20\% da produção nacional (ESTOU..., 2019). Os moradores trabalham sem parar e são orgulhosos de serem os donos do seu próprio tempo. Durante o carnaval o único momento de lazer do ano -, eles transgredem a lógica da acumulação de bens, vendem seus pertences e tiram esse tempo para descansar da rotina anual exaustiva. Apenas após a Quartafeira de Cinzas, um novo ciclo de trabalho começará. Esse é o enredo do filme Estou me guardando para quando o Carnaval chegar(2019), direção de Marcelo Gomes. O título do documentário inspira-se em um verso da canção Quando o Carnaval chegar, de Chico Buarque, transcrito na epígrafe. Tal verso dialoga com o filme pelo fato de os moradores de Toritama, apelidada de "Capital do Jeans", somente descansarem efetivamente no período do Carnaval.

Opresentetextoobjetivafazerumaanálise geral do documentário e propor uma reflexão sobre as relações de trabalho no contexto da pandemia de Covid-19, com base nos seguintes questionamentos: como conciliar trabalho e descanso em meio ao luto e isolamento social? Quais são as subjetividades mais abaladas pelo confinamento e pela situação de abandono por parte do Estado brasileiro? Apesar de ter sido lançado em 2019, dentro de um contexto pré-pandêmico, e, portanto, não apresentar dados do quanto o isolamento social tem afetado essa população, é possível fabular e reflexionar seus supostos impactos a essa população.

Incontáveis têm sido as perdas frente aos impactos do vírus Covid-19 nos últimos meses, bem como se acentuaram algumas vulnerabilidades sociais, por vezes camufladas nas sombras de uma falsa ideia de democracia vigente. Ao negar um processo que não é de hoje e "no ápice do desenvolvimento capitalista", não estamos retrocedendo, mas avançando em formas sofisticadas da barbárie (CARA, 2020). Essa frase ecoa bastante quando percebemos a quantidade de trabalhos informais que tem se firmado na atualidade. Segundo dados da Pesquisa Nacional por Amostra de Domicílios (PNAD), do Instituto Brasileiro de Geografia e Estatística (IBGE), no último trimestre de 2019, os trabalhadores informais brasileiros representaram $41 \%$ dos postos de ocupação. Na Bahia, por exemplo, o percentual da informalidade saltou para $51 \%$, ou seja, são quase 3 milhões de trabalhadores que agora enfrentam um outro problema: uma exposição maior diante do novo coronavírus (UFBA, 2020). No filme, como mencionado acima, toda a produção local de jeans se paralisa durante a semana festiva do Carnaval e só se reinicia na Quarta-feira de Cinzas, o que permite pensar qual lugar é dado ao lazer dentro desse sistema produtivo, visto que ele representa uma conquista do tempo disponível do ser humano para desenvolver potencialidades intelectuais, cognitivas, sensoriais e emocionais. Uma vez que se concede, por meio da troca de relações no mundo social, se aproximar da experiência de um pensar para além do intermédio do 
absurdo proposto por Albert Camus em O Mito do Sísifo (CAMUS, 2010), esse mito do exercício laboral se apresenta na metáfora de uma pedra a ser carregada pelo indivíduo, como um fardo interminável e sem sossego, não restando tempo para exercer suas individualidades.

Logo no início do filme nos deparamos com imagens de outdoors na entrada da cidade, contendo fotos de pessoas que supostamente representam marcas de roupas, desde já mostrando a influência da moda em Toritama. A produção nos convida a conhecer um pouco da realidade vivenciada pelos habitantes dessa cidade em Pernambuco, onde o jeans é chamado pelos moradores de "ouro azul". Eles têm esse produto como uma oportunidade laboral viável, por ser uma cidade que se articula na distribuição dessa produção, promovendo estratégias para vender o que foi produzido na semana, mais especificamente, através da Feira do Jeans, que acontece aos domingos, e O som das máquinas de corte e costura do jeans causam desconforto a quem assiste ao documentário, além de cenas que beiram à angústia pela repetição das funções executadas, tempo coletivo preenchido pelo trabalho que não finda, em uma cidade cujo nome em tupiguarani significa "terra da felicidade". No documentário, não há relatos de infelicidade no exercício laboral por parte das pessoas que foram entrevistadas, e sim de satisfação por trabalharem para si e não possuírem um patrão direto, mesmo com toda a fadiga.

A fotografia do filme e a trilha sonora são bastante responsáveis por despertar no espectador essa sensação de inquietação diante do trabalho realizado em Toritama, esses dois elementos em conjunto têm papel sinestésico nesta experiência cinematográfica. Em determinada cena narrada pelo próprio diretor, retira-se o som estridente das máquinas de costura, sendo então substituído por uma música clássica, na tentativa de tornar menos angustiante a sensação de quem assiste. Entretanto, as imagens dão conta de manter essa agonia proveniente da exaustão do ofício nas garagens da cidade, devido aos movimentos repetitivos de costura feitos pelos trabalhadores.

Otrabalhador existe de forma conflitante, de um lado, insatisfeito com a posição e com as condições às quais é submetido no processo de produção, cansaço e ritmo acelerado, no caso de Toritama, e de outro lado, a aceitação dessas condições pela necessidade de garantir sua reprodução social (SOUSA; LUNA, 2007). Ainda que seja positivo o próprio trabalhador definir o ritmo do seu trabalho, de acordo com sua necessidade financeira, existe uma situação de desamparo, visto que não são oferecidos direitos trabalhistas, principalmente nesse momento em que a pandemia explicitou muitas vulnerabilidades e desajustes na estrutura social atual.

Muitas vezes também é possível perceber esse desamparo nas jornadas de trabalho relatadas no documentário, no qual a maioria dos depoentes diz 
realizar três turnos diários, parando apenas nos horários das refeições. Logo, mesmo não possuindo patrão direto, executam trabalhos exaustivos por conta da necessidade financeira, estando igualmente dependentes do acúmulo capitalista de bens, assim como uma pessoa com carteira formalmente assinada. O sujeito que realiza tal função laboral desfruta de uma certa independência por hipoteticamente definir o próprio ritmo, mas ao final do dia, as horas corridas de trabalho e a exaustão enfatizam a vulnerabilidade que essas pessoas se encontram, evidenciando a existência de um sistema produtivo detentor do poder de definição sobre o andamento da produção.

Segundo Adalberto Cardoso e Thiago Brandão Peres (2020), cerca de seis meses após a Organização Mundial da Saúde (OMS) declarar o início da pandemia do Covid- 19, dados mostraram que a América Latina, em especial a América do Sul, se tornou a região mais afetada do mundo, no quesito número de mortes.
Tal aumento também relacionado com a informalidade do mercado de trabalho, visto que, nas atividades informais, homens e mulheres obtêm sua renda, na maioria das vezes, com transações comerciais ou com prestação de serviços por meio do contato físico direto, seja nas ruas, nos mercados populares, nas pequenas bancas de alimentos ou produtos, no trabalho doméstico e outros, observando-se que as medidas tão necessárias de isolamento impactam enormemente os meios de obtenção de renda desses trabalhadores, os deixando ainda mais em uma situação fragilizada.

A cidade de Toritama, de acordo com o que foi abordado no documentário, é um território marcado pelo trabalho, cada um na sua garagem, com suas "facções", como eles chamam esses locais, realizando suas funções produtivas para manter a produção da cidade e seu próprio sustento. Em certo momento no filme, mostra-se a parte mais rural do município, áreas que margeiam as casas e as facções onde se produzem os jeans.
Nestas regiões ainda restam criações de animais e agricultores que tentam não aderir à produção da moda, como o caso de Dona Rosilda, cujo galinheiro da sua terra foi substituído por um depósito de tecidos, evidenciando que mesmo havendo resistência por parte de alguns moradores da cidade a ceder ao jeans, o "mundo rural" têm sido absorvidos por essa cadeia produtiva, tão influente na região e no Brasil. Dessa forma, a tecnologia e a ciência, que deveriam trazer ganhos para a classe trabalhadora, intensificam a exploração da força de trabalho, submetendo-a às mais degradantes formas de exploração e informalidade. Mesmo estando "sem patrão", eles se sujeitam ao trabalho às margens da proteção legal, como única saída para a garantia de sua sobrevivência.

Joacir da Costa Pereira (2018) pontua que o lazer deveria ser um instrumento de promoção social, colaborando no rompimento da alienação do trabalho, apresentando-se

politicamente como um mecanismo inovador aos trabalhadores, na medida em que novas perspectivas de relacionamento social são estabelecidas; promovendo a integração do indivíduo livremente no seu contexto social, onde este meio serviria para o desenvolvimento de sua capacidade crítica, criativa e transformadora; e além de proporcionar condições de bem-estar físico e mental ao proletariado. Isso faz tanto sentido no caso de Toritama, que as cenas gravadas pelos próprios habitantes da cidade, quando estão na praia, quebram o ritmo um tanto exaustivo que o filme levava desde o início, em um momento de diversão e abstração das atividades laborais, e também tão aguardado durante todo o ano por eles.

Através da realidade apresentada no documentário, é possível pensar que as relações de trabalho atuais, em uma sociedade dominada pelo mercado e marcada pelos avanços tecnológicos que geram mudanças constantes, quase nunca favorecem o trabalhador, que se 
encontra constantemente apreensivo e cercado pela iminência da perda de sua posição, seja por conta da ação de uma nova máquina ou pela possibilidade de uma mudança repentina na forma de produção, que considere que ele não seja mais um elemento essencial ao processo e que culmine na sua demissão. Assim, nessa relação, constase a vulnerabilidade que o operário se encontra, obrigando-o a ceder o seu direito ao lazer, através da diminuição do seu tempo livre, às múltiplas funções laborais e renunciando às suas necessidades sociais mais primordiais, como é o caso da população de Toritama no documentário, que deseja apenas se divertir no Carnaval.

Quando esse momento chega, eles vendem eletrodomésticos e outros pertences para conseguirem realizar a viagem, deixando a cidade vazia e com poucos moradores presentes. Esse último fato é um tanto curioso, pois o município de Toritama é tão marcado no corpo desses indivíduos como um lugar de trabalho que, quando eles decidem descansar é preciso não estar ali, logo o deslocamento de saída da cidade é ponto essencial para efetivar o descanso, saem de lá como quem se retira com pressa ao final do expediente.

O trecho da música Cananéia, Iguapeellha Comprida, interpretada pelo rapper Emicida e transcrita na epígrafe, também é pertinente para a abordagem aqui apresentada. O domingo é um dia associado ao descanso, porém não trabalhar nesse dia e ter tempo livre para o lazer são privilégios desfrutados por poucos no Brasil. No verso "metrópoles sufocam", pode-se interpretar que o rapper se refere ao fato de grandes centros urbanos atuarem como palco para exploração de uma grande parcela da população, porém pequenas cidades também podem ser polos comerciais tão opressoras quanto grandes indústrias, onde soberanias roubam o direito de descanso, colateral ao caso de Toritama. No mundo do trabalho, estabilidade financeira e direitos trabalhistas que não desamparem o indivíduo, ainda mais em momentos difíceis como o período atual de pandemia, são garantias mínimas que todo operário anseia obter. Apesar disso, para aqueles que executam funções laborais de maneira informal, essa busca se encontra longe de ser alcançada.

Reflexionar como se desenvolvem as relações de trabalho e a quais condições os indivíduos estão submetidos dentro dos processos estabelecidos nessas relações, faz com que o ato de ouvir os sujeitos que estão sustentando esse sistema seja um caminho essencial para compreender o funcionamento dele. Por mais que o documentário tenha sido dirigido por uma pessoa não residente do município de Toritama, já que o diretor Marcelo Gomes é originário de Recife, foi possível entrar em contato com relatos de pessoas que habitam esse território, atualmente tão voltado pela produção de jeans e para o trabalho, e como muitos deles, a partir de óticas diversas, são marcados por essa indústria de larga escala e enorme montante de produção anual, ao mesmo tempo com dimensões tão privativas, em que muitos deles têm suas próprias máquinas e executam o trabalho em suas garagens.

Que mais produções audiovisuais com essa temática e abordagem sejam produzidas para que as relações de trabalho no contexto brasileiro sejam ainda mais discutidas nos espaços de debate, em especial, promovidos pelo cinema, ferramenta social tão eficaz na denúncia de situações degradantes para grupos de indivíduos, principalmente aqueles submetidos ao sistema capitalista, que transforma o direito ao lazer em uma prática descontextualizada da relação com o trabalho e se torna uma mera mercadoria de consumo. 


\section{REFERÊNCIAS}

CAMUS, Albert. $\mathbf{0}$ mito de Sísifo. Rio de Janeiro: Record, 2010.

CARA, Salete. Comentário sobre o filme de Marcelo Gomes - Estou me guardando para quando o carnaval chegar. Disponível em: <https:// aterraeredonda.com.br/estou-meguardando-para-quando-o-carnavalchegar/>. Acesso em: 3 de fev. de 2021. CARDOSO, Adalberto; PERES, Thiago Brandão. A "modernização das relações de trabalho", a informalidade e a pandemia. Disponível em: <https:// www.eco.unicamp.br/remir/index. php/blog/227-a-modernizacao-dasrelacoes-de-trabalho-a-informalidade-ea-pandemia>. Acesso em: 14 de fev. de 2021.

\section{ESTOU me guardando para quando}

- Carnaval chegar. Direção: Marcelo Gomes. Produção: Nara Aração e João Vieira Jr. Intérprete: Leonardo dos Santos, Karen Harley e João Vieira Jr. Roteiro: Marcelo Gomes. [S.I]: Carnaval Filmes;
Rec Produtores Associados; Misti Filmes, 2019. 86 min, son., color., digital.

MORAIS, HannahMiranda.Acalçajeansde

Toritama: o papel da produção cultural

de um artefato de moda na construção

de uma cidade. Dissertação (Mestrado em Administração) - Centro de Ciências Sociais Aplicadas da Universidade Federal de Pernambuco. Recife, 2016. Disponível em: <https://repositorio. ufpe.br/bitstream/123456789/18348/1/ Dissertacao-Hannah-Miranda-PosBanca_Final.pdf $>$. Acesso em: 14 de fev. de 2021.

\section{OLÉIAS, Valmir José. 0 lazer no aterro da}

baía sul em Florianópolis: o abandono de um grande projeto. 107f. Dissertação (Mestrado em Sociologia Política). Centro de Filosofia e Ciências Humanas da Universidade Federal de Santa Catarina. Florianópolis, 1994.

PEREIRA, Joacir da Costa. Relações de trabalho e lazer na era do capital. 21a SEMOC da UCSAL. - Programa de Pós-Graduação em Políticas Sociais e Cidadania da Universidade Católica de
Salvador. Salvador, 2018. Disponível em: <http://ri.ucsal.br:8080/jspui/bitstream/ prefix/1065/1/Rela\%C3\%A7\%C3\%B5es\%20de\%20trabalho\%20e\%20lazer\%20 na\%20era\%20do\%20capital.pdf>. Acesso em: 20 de fev. de 2021.

SOUSA, Jane Kátia Custódio; LUNA, Jucelino Pereira. Precarização einformalidade:um estudo sobre o serviço de moto-táxi em Campina Grande. III Jornada Internacional de Políticas Públicas. - Programa de Pós-Graduação em Políticas Públicas da Universidade Federal do Maranhão. São Luís, 2007. Disponível em: <http://www.joinpp.ufma.br/ jornadas/joinpplll/html/Trabalhos/EixoTematicoB/5c77f652e570c5002d4fJANE\%20 K\%C3\%81TIA\%20SOUSA_JUCELINO\%20LUNA.pdf>. Acesso em: 14 de fev. de 2021. UNIVERSIDADE Federal da Bahia. Covid-19 evidencia maior vulnerabilidade para trabalhadores informais, alerta pesquisador do ISC, 2020. Disponível em: <https:// coronavirus.ufba.br/covid-19-evidencia-maior-vulnerabilidade-para-trabalhadoresinformais-alerta-pesquisador-do-isc\#: :text=S\%C3\%A30\%20feirantes\%2C\%20 agricultores\%2C\%20ambulantes\%2C,pr\%C3\%B3ximo\%20com\%20pessoas\%20 potencialmente\%20contaminadas.>. Acesso em: 3 de fev. de 2021. 